\section{ScienceDirect}

Materials Today: Proceedings 12 (2019) 159-162 materialstoday:
PROCEEDINGS

www.materialstoday.com/proceedings

FBMT-2018

\title{
Structure and magnetism in ball-milled core-shell $\mathrm{Al}_{2} \mathrm{O}_{3} @ \mathrm{Co}$ particles
}

\author{
Ludmila Kuzovnikova, $^{\mathrm{a}, *}$, Sergey Komogortsev, ${ }^{\mathrm{b}, \mathrm{d}, \mathrm{e}}$, Elena Denisova, ${ }^{\mathrm{b}, \mathrm{d}}$, Rauf Iskhakov ${ }^{\mathrm{b}, \mathrm{e}}$, \\ Ivan Nemtsev ${ }^{c}$, Mikhail Volochaev ${ }^{b}$, Natalia Shepeta ${ }^{d}$ \\ ${ }^{a}$ Krasnoyarsk Institute of Railways Transport, Lado Ketshovelly Str., 89, Krasnoyarsk, Russia \\ ${ }^{b}$ Institute of Physics, Federal Research Center KSC SB RAS, Akademgorodok 50/38, Krasnoyarsk, 660036, Russia \\ ${ }^{c}$ Federal Research Center KSC SB RAS, Akademgorodok 50, Krasnoyarsk, 660036, Russia \\ ${ }^{d}$ Siberian Federal University, Svobodny Ave., 79, Krasnoyarsk, 660036, Russia \\ ${ }^{e}$ Reshetnev Siberian State University of Science and Technology, Krasnoyarsk, 660000, Russia
}

\begin{abstract}
The core-shell $\mathrm{Al}_{2} \mathrm{O}_{3} @$ Co particles were prepared by the ball-milling of the composite $\mathrm{Al}_{2} \mathrm{O}_{3}$-Co particles synthesized by electroless reduction. During the ball-milling process, both, the core-shell particle size and the ratio of hcp/fcc phases changed. To perform a phase analysis of the cobalt shell we used an approach based on the magnetic measurements. The use of $\mathrm{Al}_{2} \mathrm{O}_{3}-\mathrm{Co}$ composite particles as the precursors for the ball milling significantly shortens the time needed for a change in the phase composition of cobalt.
\end{abstract}

(C) 2019 Elsevier Ltd. All rights reserved.

Selection and peer-review under responsibility of the scientific committee of the V International Conference "Fundamental Bases of

Mechanochemical Technologies", FBMT-2018

Keywords: Core-shell $\mathrm{Al}_{2} \mathrm{O}_{3} @$ Co particles; ball-milling; magnetic properties.

\section{Introduction}

Magnetic particles with a core-shell structure attract attention in connection with the applications in catalysis, biomedicine, and also as precursor particles for cermets synthesis [1-5]. In this respect, new approaches to the preparation of such particles are relevant. The magnetic component in composite particles provides both new

* Corresponding author. Tel.: +7-913-833-4611.

E-mail address: kuzovnikova_la@krsk.irgups.ru

2214-7853@ 2019 Elsevier Ltd. All rights reserved.

Selection and peer-review under responsibility of the scientific committee of the V International Conference "Fundamental Bases of Mechanochemical Technologies', FBMT-2018 
possibilities for controlling the properties and their studying. Cobalt, as a component of a composite particle, allows the preparation of chemical stable magnetic particles with high magnetization and high Curie temperature [6]. Most often, magnetic metallic particles are passivated by a nonmagnetic inert shell $[1,6,7]$. The chemical stability of cobalt makes it suitable as an element of the particle shell, which leads both to fundamentally new particle properties, and to the possibility of creating new magnetic cermets [5,6]. Conventionally, cermets are made by mixing metal and oxide particles with subsequent pressing and high-temperature annealing [4,5]. Ball-milling makes it possible to achieve a uniform distribution of the metal component before pressing. If one uses powder mixtures, it requires a long time of mechanical treatment (16-20 hours) [8-11]. Earlier, we proposed a method for accelerating mechano-activation processes using core-shell composite particles [12,13]. In this paper, we use a similar approach for the preparation of $\mathrm{Al}_{2} \mathrm{O}_{3} @ \mathrm{Co}(\mathrm{P})$ particles and investigate the structure and properties of the particles obtained.

\section{Experiment}

The initial $\mathrm{Al}_{2} \mathrm{O}_{3} / \mathrm{Co}(\mathrm{P})$ composite particles consist of granular $\mathrm{Al}_{2} \mathrm{O}_{3}$ cores (50 mass \%), surrounded by a shell of $\mathrm{Co}_{95} \mathrm{P}_{5}$ particles. The Co-P particles were deposited on $\mathrm{Al}_{2} \mathrm{O}_{3}$ surface by electroless plating $[14,15]$ as described in our previous study [16]. The average size of $\mathrm{Al}_{2} \mathrm{O}_{3}$ granules is about $300 \mathrm{~nm}$. The milling of the composite particles was performed in the planetary ball mill AGO-2U with stainless-steel vials and balls during 15, 30, 45, 60, 75 , and $90 \mathrm{~min}$. The ball-to-powder weight ratio is $20: 1$, ball acceleration was $10 \mathrm{~g}$. The $\mathrm{Co}_{95} \mathrm{P}_{5}$ particles were also milled under the same conditions. The morphology and the composition of the powders were analyzed using scanning and transparent electron microscopes (Carl Zeiss EVO 60 and Hitachi TM3000 with X flash $430 \mathrm{H}$ detector, Bruker; HT7700, Hitachi). The crystalline structure of the composite powders was determined using a DRON-4 X-ray diffractometer operating with $\mathrm{Cu} \mathrm{Ka}$ radiation. Magnetic measurements were performed in the external field range up to $14 \mathrm{kOe}$ and at $77-300 \mathrm{~K}$ using a vibrating sample magnetometer designed at the Kirensky Institute of Physics [17].

\section{Results and discussion}

According to microscopic images (SEM and TEM), the initial particles of $\mathrm{Al}_{2} \mathrm{O}_{3}-\mathrm{Co}_{95} \mathrm{P}_{5}$ do not always have a continuous coating of cobalt. The small $\mathrm{Co}_{95} \mathrm{P}_{5}$ particles are located on the surface of some large $(\sim 0.5 \mu \mathrm{m}) \mathrm{Al}_{2} \mathrm{O}_{3}$ particles. Ball milling for 45 minutes leads to an increase in the average particle size and width of the particle size distribution. With a further ball-milling up to 75 minutes (see Fig. $1 \mathrm{~b}$ ), the width of the distribution somewhat decreases, but the average particle size is greater than before milling. First of all, cobalt should be subjected to plastic deformation during the milling process. The Co particles immobilized on the surface of the $\mathrm{Al}_{2} \mathrm{O}_{3}$ granules are plastically deformed, leading to the formation of a continuous coating of the particle. This is confirmed by the behavior of the X-ray diffraction spectra. The X-ray diffraction patterns of particles both $\mathrm{Al}_{2} \mathrm{O}_{3} @ \mathrm{Co}_{95} \mathrm{P}_{5}$ and $\mathrm{Co}_{95} \mathrm{P}_{5}$ were characterized by a set of hcp-Co reflexes supplemented with $\mathrm{Al}_{2} \mathrm{O}_{3}$ peaks in the case of composite particles. The peaks of $\mathrm{Al}_{2} \mathrm{O}_{3}$ disappeared after 15 minutes of milling [16]. The fact is that a continuous metallic coating of cobalt effectively shields X-ray radiation. This results in the detector receiving only the signal from the cobalt coating. In addition, the data of Energy-dispersive X-ray spectroscopy (EDX analysis) show both the presence of the Co shell and the fact that the aluminum and cobalt atoms are uniformly distributed over the surface of the particle (see Fig. 1 a). Particles of $\mathrm{Co}_{95} \mathrm{P}_{5}$ during ball-milling undergo allotropic transformations which results in appearing of fcc- $\mathrm{Co}(\mathrm{P})$ phase and subsequent changes in its quantity $[10,16]$. Similar transformations would occur in the cobalt shell of particles. However, the cobalt reflections on the X-ray diffraction pattern are significantly broadened by the milling, making it difficult to reliably estimate the phase composition [16]. Therefore, for phase analysis, we use an indirect method based on measuring the approach to magnetic saturation curves. The field dependences of magnetization were measured using a vibrating sample magnetometer [17] and presented in fig.2a. 

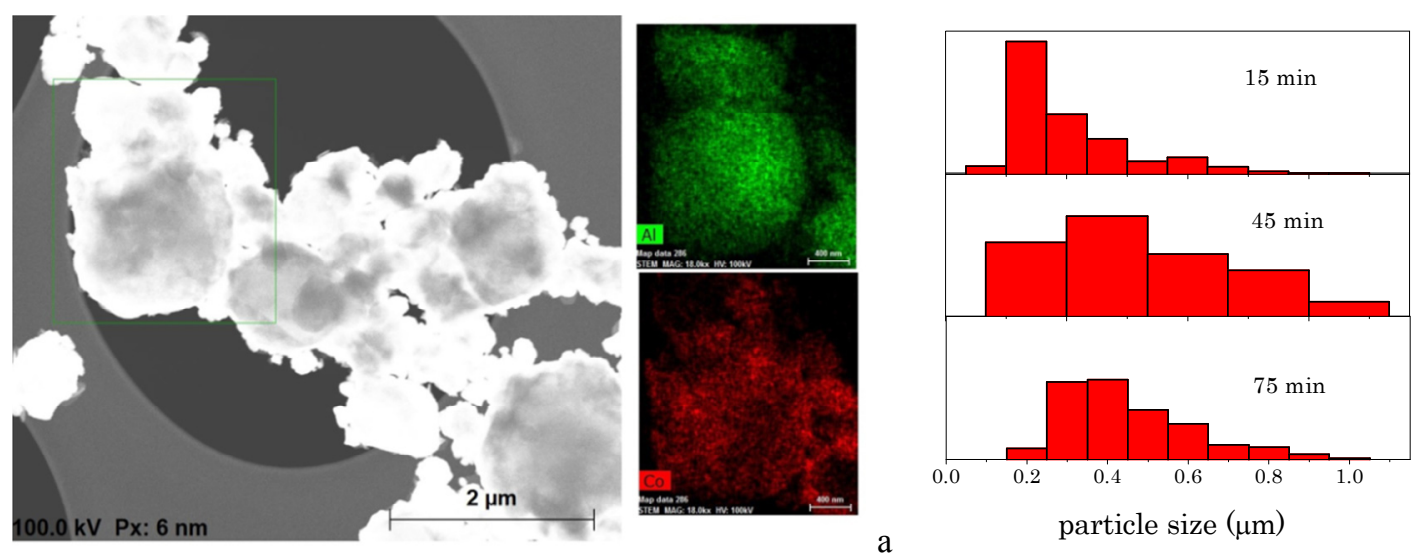

b

Fig. 1. (a) TEM image of A12O3@Co particles and elemental maps in one particle (after 30 min. milling) (b) Particle size distribution by number for different times of milling.
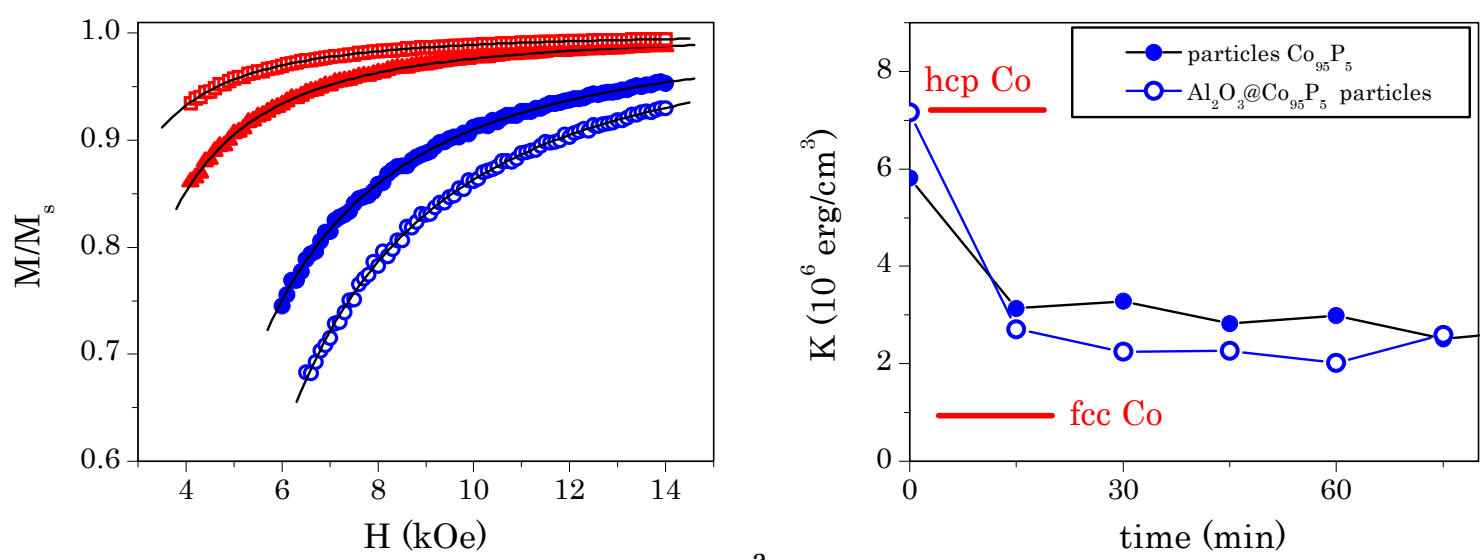

Fig. 2. (a) Approach to magnetic saturation in the particles before and after the ball-milling. The filled circles correspond to the initial particles of $\mathrm{Co}_{95} \mathrm{P}_{5}$; filled triangles correspond to $\mathrm{Co}_{95} \mathrm{P}_{5}$ particles after 60 minutes of milling. Empty circles correspond to initial particles $\mathrm{Al}_{2} \mathrm{O}_{3} @ \mathrm{Co}_{95} \mathrm{P}_{5}$; empty squares correspond to particles $\mathrm{Al}_{2} \mathrm{O}_{3} @ \mathrm{Co}_{95} \mathrm{P}_{5}$ after 60 minutes of milling. Solid lines correspond fitting by Eq.1 (b) The magnetic anisotropy constant of particles for different times of milling.

The approach to magnetic saturation curves in applied fields greater than 4 kOe follows the Akulov's law (see Fig. 4) [18]:

$$
M(H)=M_{S} \cdot\left[1-\frac{1}{15}\left(\frac{K}{M_{S} \cdot H}\right)^{2}\right]
$$

where $K$ and $M_{s}$ are the magnetic anisotropy constant and the saturation magnetization of the particles, respectively, $M(H)$ is the magnetization in the applied field $H$. The magnetic anisotropy constant, calculated as a parameter of the best fitting by Eq.1, significantly changes during the milling process. The magnetoelastic contribution to the constant $K$ is low because of the small magnetostriction in cobalt. Therefore, the main contribution comes from the magnetocrystalline anisotropy. The anisotropy constant of particles in the initial state is somewhat larger than the constant of hcp-Co, and after milling it becomes much lower than in hcp-Co, but higher than in fcc Co. According to 
[19] $\mathrm{Co}_{95} \mathrm{P}_{5}$ particles contain both hcp-Co and fcc-Co phases. To estimate the fraction of the fcc phase we used the following equation for the effective magnetic anisotropy constant [19]:

$$
\begin{aligned}
& K=\sqrt{K_{f c c}^{2} \cdot x_{f c c}+K_{h c p}^{2} \cdot\left(1-x_{f c c}\right)}, \\
& x_{f c c}=\frac{K_{h c p}^{2}-K^{2}}{K_{h c p}^{2}-K_{f c c}^{2}}
\end{aligned}
$$

Calculations based on the data in Fig. $2 \mathrm{~b}$ show that, with milling, the fraction of the fcc-Co varies from 0 to 0.89 after 60 minutes of milling in $\mathrm{Al}_{2} \mathrm{O}_{3} @ \mathrm{Co}_{95} \mathrm{P}_{5}$ particles. For $\mathrm{Co}_{95} \mathrm{P}_{5}$ particles, we have a change from 0.35 in initial particles to 0.85 for the particles after 60 minute of milling. In addition the main change in the phase composition occurs during the first 15 minutes of milling. This is considerably less than the times of similar transformations $(\sim 10 \mathrm{~h})$ of the powder mixtures of $\mathrm{Al}_{2} \mathrm{O}_{3}$ and Co particles $[8-10,16]$.

\section{Conclusions}

We used the ball-milling of the composite $\mathrm{Al}_{2} \mathrm{O}_{3}$-Co particles synthesized by electroless reduction to form the core-shell $\mathrm{Al}_{2} \mathrm{O}_{3} @$ Co particles. To investigate the features of the ball-milling process we performed both, structural and magnetic analysis. We found that during ball-milling process continuous cobalt shell was formed, while particle size and the ratio of hcp/fcc phases in the cobalt shell changed. To analyze the phase composition of the cobalt shell, we used an approach based on the magnetic measurements. The use of $\mathrm{Al}_{2} \mathrm{O}_{3}-\mathrm{Co}$ composite particles as the precursors for the ball milling significantly shortens the time needed for a change in the phase composition of cobalt, relative to the usage of $\mathrm{Al}_{2} \mathrm{O}_{3}$ powder mix.

\section{Acknowledgements}

This work was supported by Russian Foundation for Basic Research, Government of Krasnoyarsk Territory, Krasnoyarsk Region Science and Technology Support Fund to the research project № 18-42-240006.

\section{References}

[1] B. Kalska-Szostko, U. Wykowska, D. Satuła, Colloids Surfaces A Physicochem. Eng. Asp. 481 (2015) 527-536.

[2] O. Hudak, M. Hudak, Adv. Mater. Sci. Eng. 2010 (2010) 1-6.

[3] Y. Jing, S.-H. He, J.-P. Wang, Appl. Phys. Lett. 102 (2013) 253102.

[4] S.I. Cha, S.H. Hong, G.H. Ha, B.K. Kim, Int. J. Refract. Met. Hard Mater. 19 (2001) 397-403.

[5] W.P. Tai, T. Watanabe, J. Mater. Sci. 33 (1998) 5795-5801.

[6] S.P. Gubin, ed., Magnetic Nanoparticles, Wiley, 2009.

[7] W. Liu, W. Zhong, Y.W. Du, J. Nanosci. Nanotechnol. 8 (2008) 2781-2792.

[8] E. Menéndez, J. Sort, S. Suriñach, M.D. Baró, J. Nogués, J. Mater. Res. 22 (2007) 2998-3005.

[9] N.-R. Park, I.-J. Shon, Mater. Trans. 54 (2013) 1049-1052.

[10] W.S. Yeo, H.S.C. Metselaar, Met. Nano-Metal Chem. 38 (2008) 341-345.

[11] J. Li, X. Ni, G. Wang, J. Alloys Compd. 440 (2007) 349-356.

[12] R.S. Iskhakov, L.A. Kuzovnikova et al., Tech. Phys. Lett. 30 (2004) 60-63.

[13] R.S. Iskhakov, E.A. Denisova, et al., J. Optoelectron. Adv. Mater. 10 (2008) 1043-1047.

[14] R.S. Iskhakov, L.A. Chekanova, E.A. Denisova, Phys. Solid State. 41 (1999) 416-419.

[15] L.A. Chekanova, E.A. Denisova, R.S. Iskhakov, IEEE Trans. Magn. 33 (1997) 3730-3732.

[16] E.A. Denisova, L.A. Kuzovnikova, R.S. Iskhakov, A.A. Bukaemskiy, E.V. Eremin, I.V. Nemtsev, J. Appl. Phys. 115 (2014) $17 B 530$.

[17] D.A. Velikanov, Patent RF N 2341810, publ. 20.12.2008, bull. No 35.

[18] N.S. Akulov, Zeitschrift fur Phys. Phys. 69 (1931) 822-831.

[19] L.A. Chekanova, E.A. Denisova, O.A. Goncharova, S.V. Komogortsev, R.S. Iskhakov, Phys. Met. Metallogr. 114 (2013) $122-128$. 